\title{
Forecasting Greenhouse Gas Emissions from Urban Regions: Microsimulation of Land Use and Transport Patterns in Austin, Texas
}

\author{
Sumala Tirumalachetty \\ Graduate Research Assistant \\ Department of Civil, Architectural and Environmental Engineering \\ The University of Texas at Austin \\ 6.9 E. Cockrell Jr. Hall \\ Austin, TX 78712 \\ sumala@mail.utexas.edu
}

Kara M. Kockelman

(Corresponding author)

Professor and William J. Murray Jr. Fellow

Department of Civil, Architectural and Environmental Engineering

The University of Texas at Austin

6.9 E. Cockrell Jr. Hall

Austin, TX 78712

kkockelm@mail.utexas.edu

Presented at the 89th Annual Meeting of the Transportation Research Board, January 2010 and published in Journal of Transport Geography 33 (2013)

\section{ABSTRACT}

Policymakers, planners, engineers, and others seek effective ways to anticipate and manage greenhouse gas (GHG) emissions for a sustainable future. Here, a microsimulation model was developed to forecast Austin's demographic and firmographic attributes over time, using a variety of national and local, aggregate and disaggregate data sets. Year 2030 household energy demands and GHG emissions estimates are compared under five different land use and transport policy scenarios. Application of an urban growth boundary provided the lowest increase in overall vehicle miles travelled (VMT) and GHG emissions, while network additions resulted in the highest rates of increase. Average energy consumption per household is estimated to fall over time (by 11-19\%, depending on the scenario), but the region's overall energy consumption is estimated to increase dramatically -- by nearly $88 \%$ in terms of home energy consumption (in the trend scenario) and $108 \%$ in the transport sector, relative to the 2005 base-year conditions. Such increases are considerably higher than proposed GHG targets, presenting a serious energy and emissions challenge for Austin as well as other U.S. regions.

Keywords: land use modeling, urban system forecasting, microsimulation, energy consumption, greenhouse gas emissions, travel demand modeling 
Climate change is an issue that has received much attention in the past few years. Energy demands associated with travel, space conditioning and powering household devices are leading contributors of greenhouse gas (GHG) emissions. There is a growing awareness that the way of life practiced in the world's wealthier countries accompanied by increasing energy needs is unsustainable (Salomon et al. 2002). Energy consumption within and across urban regions has distinct spatial and urban dimension (Moeckel et al. 2002). Increasing income levels and continuing low transport costs lead urban workers to choose housing locations in suburban locations in order to enjoy lower land prices and larger homes. This results in higher urban and rural demands for travel and energy.

The U.S. Energy Information Administration (EIA 2005) estimates that the nation's transportation and residential sectors contribute $28 \%$ and $17 \%$ of total U.S. emissions, respectively. U.S. GHG emissions rose $13 \%$ between 1990 and 2003, while those from the associated GHG emissions), one must anticipate vehicle holdings and usage patterns. In addition to transport, households use electricity, natural gas and other energy sources regularly for space conditioning and powering household devices. Emissions from U.S. buildings continue to grow at over $2 \%$ annually (EIA 2005). While U.S. energy demands per capita have fallen over $25 \%$ in the last 25 years, the nation's population increases have more than offset any potential emissions savings. Accurate prediction of future travel demand and energy consumption patterns is the first step in planning development and controlling future emissions. Understanding lifecycle transitions in the demographic and firmographic profiles of households and firms and changes in the trip-making process are critical for accurate forecasting. Technological advances now provide the computational capacity to trace such regional actors individually and microsimulation offers a convenient platform for anticipating these emissions at a disaggregate level. Other researchers have sought to anticipate behavior, especially households and, to a lesser extent, firms (see, e.g. Miller et al. 1998, Timmermans 2003, Waddell et al. 2003, Salvini et al. 2005, and Maoh et al. 2005). Hensher (2007) used an integrated transport-land use simulator to anticipate GHG emissions from the transport sector in Sydney, Australia. Tirumalachetty et al. (2009) developed a framework to anticipate location choices and energy consumption of households and firms over time in Austin, Texas. This paper is an extension of that work, where GHG emissions are compared under a variety of scenarios.

\section{MODEL DEVELOPMENT}

Microsimulation models seek to replicate the evolution of individual agents like households and firms and thus are generally data intensive. In the absence of panel data for Austin households and firms, this study develops a microsimulation model to forecast demographic and firmographic characteristics, using various national and local, aggregate and disaggregate data sets, under various assumptions regarding life-cycle events. The sub-models include models of demographic development, household formation, firm lifecycles, housing and vehicle choices. One key advantage of microsimulation lies in its detailed outputs, which can be manipulated (and aggregated) in a number of ways. This section outlines the different processes modeled in the system; more details on these processes and their accompanying data sources can be found in Kumar (2007) and Tirumalachetty (2009). 
The Austin metropolitan region consists of 1,074 traffic analysis zones (TAZs) spread over three counties: Travis, Williamson and Hays. The region is shown in Figure 1. For the 2005 base year of 2005, there are approximately 450,000 households in the region and over one million people. In model application, households and firms evolve by application of the sub-models described below.

\section{Overview of Modeling Framework}

The systems household evolution relies on models for births, deaths, marriages, divorces, in and out migration, all modeled as logit transitions (Tirumalachetty et al. 2009). Markov transition matrices are used to model firm size transitions. Vehicle acquisition and use models capture holdings in a dynamic context, along with household level changes. The travel demand model uses standard approaches: least square regression models for trip generation by households; joint multinomial logit models for destination, mode, and time-of-day (TOD) choice; constant vehicleoccupancy assumptions; and static deterministic user equilibrium traffic assignment routines. Lemp (2007) provides more details on the travel demand model. In order to appreciate travel cost changes (per mile) the changes in emissions due to changing vehicle ownership patterns, traffic assignment was done using a multi-class assignment in TransCAD (Caliper Corporation, 2002).

Household vehicle fleets were classified into five average fuel economy categories (less than 20 mpg, 20 to $22 \mathrm{mpg}, 22$ to $24 \mathrm{mpg}, 24$ to $26 \mathrm{mpg}$, and over $26 \mathrm{mpg}$ ), based on the average of vehicles held by each synthetic household. Trips generated in each zone were distributed among the five categories, as per local household fuel-economy shares. Commercial and external trips were loaded as separate classes, for a total of seven assigned classes. For GHG emissions estimation, fleet-wide average fuel economy $(20 \mathrm{mpg})$ was assumed for external trips and $8 \mathrm{mpg}$ is used for commercial trips.

Figure 2 shows the overall simulation framework. Households and firms are added and removed at one-year intervals. Firm and household populations are assumed to evolve independently (but growth rates are pre-specified, thus ensuring regional balance), and the commercial and household trips are combined and loaded onto the transportation network. Travel demand modeling was performed every 5 years, so travel times and accessibility measures could be updated for the household and firm location modules.

\section{Policy Scenarios}

Five scenarios were used to forecast changes in land use patterns and household and firm energy demands: (a) Business as usual (BAU), (b) Imposition of an urban growth boundary (UGB), (c) Gas tax and road tolls (PRICING), (d) Expanded (doubled) capacity of Austin's primary freeway (EXPCAP) and (e) Introduction of a new highway bypass (SH130). In the BAU, no changes are made to the transportation network. This scenario serves as a basis for comparing results across all other scenarios. In the UGB scenario, the location alternatives of all new households and firms are restricted to the 617 (out of 1,074) TAZs that enjoyed at least two job equivalents per acre in 2005 or were contiguous with such zones (Figure 3). In the third scenario (PRICING), gas prices are set to \$6 per gallon (rather than the base level of \$3/gallon) and a 
fixed toll of 10 cents per mile is imposed on all roads ${ }^{1}$. The last two scenarios investigate changes in the location patterns and energy demands due to expansion of Austin's freeway system. In the expanded capacity scenario (EXPCAP), capacity along the regions' most congested transportation corridor - I-35(nearly 80 center-line miles in length) is doubled. In the last scenario, a new highway, SH 130, is introduced into the network and its effect is studied. SH-130 is a 4-lane, 49-mile highway, extending from Interstate 35 (I-35) north of Georgetown southward to U.S. 183, southeast of Austin (www.sh130.com). It passes though Williamson and Travis counties and bypasses Austin's congested core, along with famously congested sections of I-35. Figure 3 highlights the I-35 and SH 130 corridors.

\section{RESULTS}

Microevolution of all Austin firms and 10 percent of the region's households was carried out using yearly transitions while travel demand modeling was performed externally once every five years, as in any other region level microsimulation. The model's computational demands present a major challenge. Tracking 45,180 households (a 10-percent sample) and more than 100,000 individuals over a span of 25 years, with time-of-day and mode choice models, is tedious, taking more than 3 days to run on a standard desktop machine (2GB RAM and 2.66GHz). Over the 25year period, the number of households and persons are simulated to grow by $109 \%$ and $70 \%$, respectively. Average household size is expected to fall by $7 \%$ by 2030 , while real income per household is expected to remain largely unchanged and average vehicle ownership (per household) increases by just $10 \%$. During the simulation period, the number of firms is expected to grow at $32 \%$ with a steady increase in all sectors. With respect to household locations and GHG emissions, simulations suggest interesting differences across scenarios. These are explained in detail below.

\section{Location Choices}

Households exhibit strikingly different location patterns under the five scenarios. As expected, the models predict much greater household density in centrally located zones when a growth boundary policy is implemented (UGB) as compared to the BAU case. In the expanded capacity scenario (EXPCAP), households clearly shift towards zones alongside I-35. Housing types relate closely to location choices. In the UGB scenario, the shift to multi-family housing units is greater (60\% by 2030) because of relatively scarce land in development permitted zones. A similar increase in multi-family units is seen in the last two scenarios, as policies network expansion raise central area accessibility values, attracting households back to Austin's center, while densifying development alongside its major highway corridors. In general, firms tend to locate in central zones, with no evidence of significant location-pattern differences across scenarios.

\section{Vehicle Choices}

Table 1 list vehicle counts by type in year 2030. Average vehicle ownership is highest in the BAU scenario, and lowest in the pricing scenario, as expected. Under BAU more households are located in rural zones which are associated with higher vehicle ownership. The effect of a gas tax (in the pricing scenario) is somewhat apparent in the number and composition of year 2030 vehicles, as the model predicts slight reductions in the shares of large cars and pickups, thus

\footnotetext{
${ }^{1}$ Austin's network consists of 10,594 links in the base year.
} 
allowing for a higher percentage of compact and subcompact cars (due to higher fuel efficiency than large cars) as well as SUVs. SUVs are more fuel efficient than their closest substitute pickups and vans. Personal vehicle fleet composition is nearly identical in the EXPCAP and SH130 scenarios, with a reduction in the share of pickups and an increase passenger car shares, relative to the BAU scenario.

\section{Vehicle Miles Travelled and GHG Emissions}

Figure 4 shows VMT for each of the seven personal-vehicle classes across the five scenarios. Consistent with vehicle ownership shares, the BAU scenario has the largest fraction of VMT in the lowest fuel economy class (thanks to its relatively high pickup-truck share). The base year (2005) had 4 million weekday trips generating over 40 million VMT. VMTs generated under the scenarios are reported in Table 2 along with average VMT-weighted volume-to-capacity (v/c) ratios and speeds. In the BAU case, VMT is forecasted to increase $130 \%$ by 2030. Implementation of an UGB restricts the predicted rise to 98 percent, whereas the pricing scenario restricts VMT growth to $120 \%$. The highest increase is evident SH130 scenario (150 \%), nearly $10 \%$ higher VMT than BAU. Expansion of I-35 also increases regional VMT by $6 \%$ as compared to the base case in 2030. The split of VMT among the different times of day is fairly constant across scenarios except in the pricing scenario, where more trips are observed in the offpeak time period. V/C ratios and average speeds are higher in the UGB scenario as compared to the BAU scenario, which is expected, due to densification of central zones, In contrast V/C ratios drop and average speeds increase in EXPCAP and SH130 scenarios.

To translate VMT changes into GHG emissions, EPA (2006) conversions are used. A gallon of gasoline is assumed to produce 8.8 kilograms (or 19.4 pounds) of CO2. EPA's computer model for estimating highway vehicles emission, MOBILE 6, estimates fleetwide fuel economy as 20.3 mpg, which is used for external trips. Multi-class assignment of trips based household level fuel economies of vehicles were used for internal trip making by households. The estimates provided here are for vehicle emissions only, and do not include lifecycle emissions, associated with the production of vehicles and their maintenance and disposal. Table 3 provides these results. Laws passed recently require the nation's fleet of new light-duty vehicles to average 35 miles per gallon by the year 2016. Plug-in hybrid electric vehicles will be selling soon and are expected to save owners $50 \%$ or more in fuel costs. Such policies and technologies are essential to significantly reduce carbon emissions from the transport sector.

\section{Household Energy Demand}

Household energy demand was estimated by applying the regression model results from Residential Energy Consumption Survey (RECS) data (Tirumalachetty et. al 2009) for each household. Based on National Center for Climatic Data (NCDC 2006) estimates, the number of Heating Degree Days (HDD) and Cooling Degree Days (CDD) for the Austin region (relative to a base temperature of 65 degrees Fahrenheit) are 1674 and 2974. These values are assumed constant throughout the simulation period (though climate changes could increase both values, by making weather patterns more extreme. $\mathrm{CO} 2$ equivalents for these forms of energy in Texas are 1.46 lbs CO2 per kWh (EIA 2005) and 117.8 lbs CO2 per Btu for natural gas (EIA 2005). Thanks to shift toward multi-family housing units, energy consumption is forecasted to increase at a much lower rate than VMT, as seen in Table 3. Nevertheless, total energy demand and, 
presumably, associated GHG emissions are estimated to rise at alarming rates. Given that world leaders and climate-aware experts seek steep GHG cuts in developed countries like the U.S. (e.g., hitting 1990 levels by 2020 and an $80 \%$ reduction by 2050 [IPCC 2007]), a shift to renewable feedstocks (like wind, cellulosic fuels, and solar power), application of emerging coal technologies, and improvements in power generation and transmission practices may help offset many (if not most) of these potential emissions increases. Anticipating such technology shifts is beyond the scope of this paper. Nevertheless, such shifts seem clearly needed, to come anywhere close to hitting targets.

\section{Per Capita Emissions}

Emissions from residential and transportation sectors sum to 9.68 tons per Austinite per year in the BAU scenario (Table 4). This is $58 \%$ lower than the nation-wide average value of 23.4 tons per capita in 2005 (WRI 2009), mainly because industrial and commercial energy contributions and other forms of transportation (e.g., air travel) are not included here.

In the UGB scenario, as mentioned earlier, development is constrained to zones with two or fewer job equivalents per acre. This resulted in higher central zone densities along with a shift to multifamily housing units $(60 \%$ of households by 2030 , versus $55 \%$ in the BAU scenario, and $63 \%$ in year 2005). This also resulted in a slightly higher share of subcompact and compact cars, and thus a lower rate of related energy demands and GHG emissions. Overall, this scenario's per capita emissions stand at 8.65 tons per year in 2020, which is $11 \%$ lower than the BAU scenario's level. In the PRICING scenario, the shares of compact and subcompact cars are also higher resulting in $4 \%$ lower per capita $\mathrm{GHG}$ emissions from the transportation sector. In the last two scenarios, the per capita GHG emissions are higher (by 3.5 and 2.3\%, respectively, in EXCAP and SH130 scenarios), which is mainly due to higher emissions from transport fuel consumption, due to longer travel distances. Thus UGB policy appears most effective in curbing emissions from both transportation and household energy consumption.

Across the scenarios, the total number of households and firms vary by less than $3 \%$ (for households) and 6\% (for firms). Greater variation is seen in the case of firm counts due to their smaller overall values and the discrete nature of firm existence and location choice. Firms have a somewhat unbelievably high preference for central zones when selecting new locations in all the scenarios, mainly due to the use of cross-sectional data sets for location choices.

\section{SUMMARY AND CONCLUSIONS}

This paper describes the microsimulation of household and firm evolution, vehicle ownership, land use patterns, and related greenhouse gas emissions by 2030 under five distinctive scenarios. Households and firms are key agents of urban growth, and systems-based modeling techniques help anticipate their long-term location and home-type choices, vehicle purchase decisions, and travel patterns, thereby facilitating analysis of carbon emissions under a range of meaningful policies. Travel demand model results suggest an increase in regional VMT when network capacity is increased, which is no surprise. The UGB scenario provided the lowest increase in overall VMT and modeled GHG emissions. 
Annual per capita emissions in Austin's 2030 UGB scenario are estimated to be 8.65 tons, which is $11 \%$ lower than the BAU scenario's level. The number of (personal) vehicles is estimated to jump 143 percent over the 25 -year forecast period, while average vehicle ownership (per household) is simulated to increase just 19 percent in the BAU scenario. Even though average GHG emissions per household are estimated to fall, the region's overall energy consumption estimates rise (by nearly $88 \%$ for home energy and $108 \%$ for transport-related energy, under the BAU scenario). Such forecasts present a tremendous energy-security and climate challenge. These levels are considerably higher than proposed emissions targets, which seek a 17 percent cut by 2020 and more than 80 percent cut by 2050 .

While important challenges in this work involve lack of quality data sets and high run times, the microsimulation approach was found feasible, even for a region as complex as Austin. A wide variety of data sets and behavioral models were used to estimate future GHG emissions based on household and firm demographics, vehicle ownership and use decisions, and building choices. And the calibrated behaviors and system simulation provide useful insights into future energy demands. Such insights may prove priceless for the challenging investment and policy decisions that confront our communities, at the local, regional and planetary levels.

\section{ACKNOWLEDGEMENTS}

We wish to thank Southwest University Transportation Center (SWUTC) for providing financial support for this work and Annette Perrone for editing assistance. We also want to thank Saurabh Kumar and Jason Lemp whose earlier work provided the basic foundations for this work.

\section{REFERENCES}

Brown, M.A., F. Southworth, and T.K. Stovall. 2005. Towards a Built Climate Friendly Environment. Pew Center. http://www.pewclimate.org/docUploads/Buildings_FINAL.pdf. Accessed 25th October 2007.

Caliper Corporation. 2002. Caliper Corporation, TransCAD transportation GIS software, Caliper Corporation, America.

Energy Information Administration (EIA). 2005. Voluntary Reporting of Greenhouse Gases Program (Fuel and Energy Source Codes and Emission Coefficients).

http://www.eia.doe.gov/oiaf/1605/coefficients.html. Accessed June 20, 2008.

Environmental Protection Agency (EPA). 2006. Greenhouse Gas Emissions from the U.S. Transportation Sector: 1990-2003. http://epa.gov/otaq/climate/420r06003.pdf. Accessed July 23, 2008 .

Hensher, D. A. 2007. Climate Change, Enhanced Greenhouse Gas Emissions and Passenger Transport - What can we do to make a difference? 
Intergovernmental Panel on Climate Change (IPCC). 2007. "Climate Change 2007-The Physical Science Basis, Contribution of Working Group I to the Fourth Assessment Report of the

Kumar, S. 2007. Microsimulation of Household and Firm Behaviors: Coupled Models of Land Use and Travel Demand in Austin, Texas. Master's Thesis. Department of Civil Engineering, The University of Texas at Austin.

Kumar, S. and K. Kockelman. 2008. Tracking the Size, Location and Interactions of Businesses: Micro-simulation of Firm Behavior in Austin, Texas. Proceedings of the 87th Annual Meeting of the Transportation Research Board, Washington DC, 12-15 January 2008.

Lemp, J. 2007. Travel Demand Forecasting Models: Development, Application, and Comparison of Aggregate and Activity-Based Approaches for the Austin, Texas Region Master's Thesis. Department of Civil Engineering, The University of Texas at Austin.

Maoh, H.F., P.S. Kanaroglou and R.N. Buliung. 2005. Modeling the Location of Firms within an Integrated Transport and Land-use Model for Hamilton, Ontario. CSpA Working Paper 006. Centre for Spatial Analysis. McMaster University.

Miller, E. J., and P. A. Salvini. 1998. The Integrated Land Use, Transportation,Environment (ILUTE) Modeling System: A Framework. Proceedings of the 77th Annual Meeting of the Transportation Research Board, Washington DC, 12-15 January 1998.

Moeckel, R., C. Schürmann and M. Wegener (2002) Microsimulation of land use, Proceedings of the 42nd European Congress of the Regional Science Association, Dortmund, 27-31 August 2002.

National Climatic Data Center (NCDC) 2006. Comparative Climatic Data for the United States through 2006 http://www1.ncdc.noaa.gov/pub/data/ccd-data/CCD-2006_fixed.pdf . Accessed February 182008.

Salomon, I., Waddell, P., Wegener, M. 2002. Sustainable life styles? Microsimulation of Household Formation, Housing Choice and Travel Behavior. In: Social Change and Sustainable Transport 125-131. Indiana University Press, Bloomington, IN.

Salvini, P.A., and E.J. Miller. 2005. ILUTE: An Operational Prototype of a Comprehensive Microsimulation Model of Urban Systems. Networks and Spatial Economics 5: 217-234.

Tirumalachetty, S. 2009. Microsimulation of Household and Firm Behaviors: Anticipation of Greenhouse Gas Emissions- in Austin, Texas. Master's Thesis. Department of Civil Engineering, The University of Texas at Austin.

Tirumalachetty, S., K. Kockelman and S. Kumar. 2009. Micro-Simulation Models of Urban Regions: Anticipating Greenhouse Gas Emissions from Housing \& Transport in Austin, Texas. Proceedings of the 88th Annual Meeting of the Transportation Research Board. (2009). 
Timmermans, H. 2003. The Saga of Integrated Land Use-Transport Modeling: How Many More Dreams Before We Wake Up? Presented at 10th International Conference on Travel Behavior Research, Lucerne, Switzerland, 2003.

Waddell, P.A., A. Borning, M. Noth, N. Freier, M. Becke, and G. Ulfarsson. 2003. Microsimulation of Urban Development and Location Choices: Design and Implementation of UrbanSim. Networks and Spatial Economics 3(1): 43-67.

WRI. World Research Institute 2009. Climate Analysis Indicators Tool (CAIT) version 6.0. (Washington, DC: World Resources Institute, 2009). Available at http://cait.wri.org. Accessed April 202009

\section{List of Figures}

Figure 1: The Austin Region (Travis, Williamson and Hays Counties)

Figure 2: UGB, I-35 and SH 130 in the region

Figure 3: Illustration of Austin's Example Urban Growth Boundary, I-35 Corridor and SH 130 Corridor

Figure 4: Vehicle Miles Traveled by Roadway Class in 2030 across Scenarios

\section{List of Tables}

Table 1: Vehicle Fleet Composition Estimates in 2030 by Scenario

Table 2: Network VMT, Greenhouse Gas Emissions, V/C Ratios and Speeds in 2030

Table 3: Household Energy Demand and GHG Emissions

Table 4: Year 2030 Per Capita Carbon Emissions 


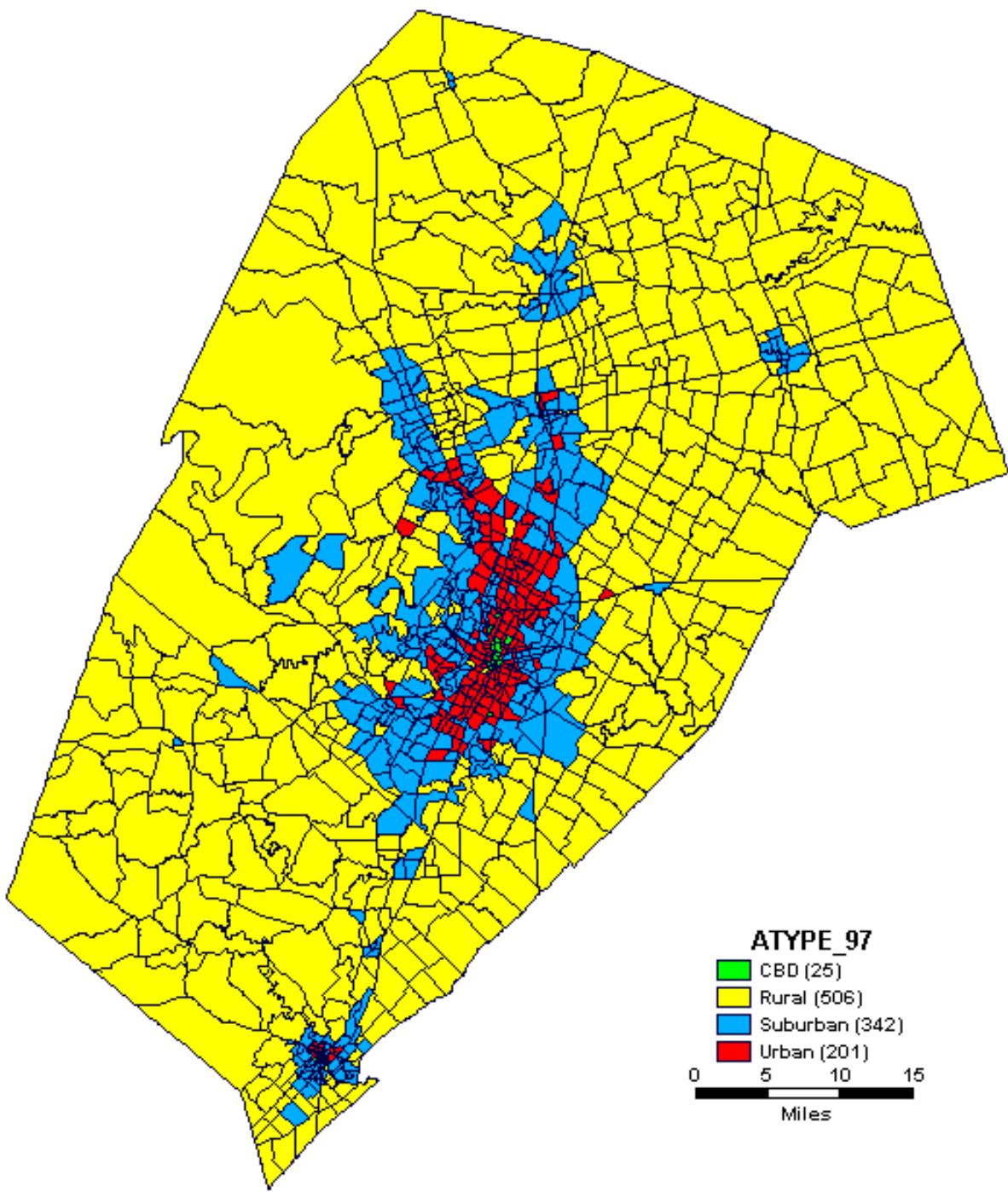




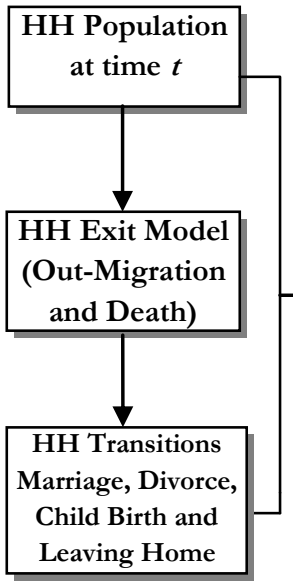

HH Birth Model (In-

Migration, Divorce

and Leaving Home)

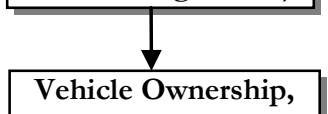

Transactions Model

385

386

387

388

389

390

391

392

393

394

395

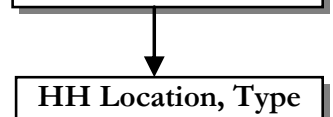

Choice Model

HH Population at time $t+1$

Electricity \& Natural Gas

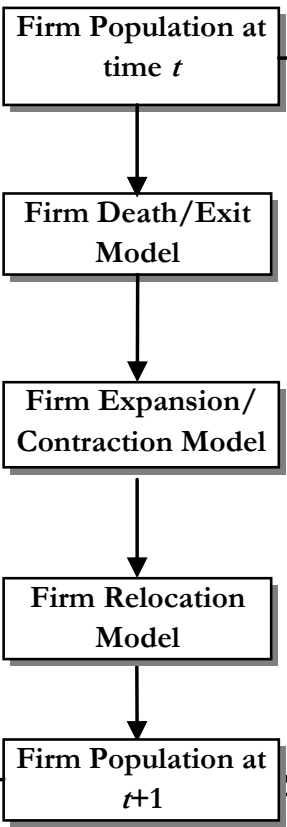

Firm Birth Model

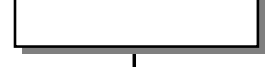

Firm Location

Choice Model
Distribution
Commercial Trip

Generation and Distribution 


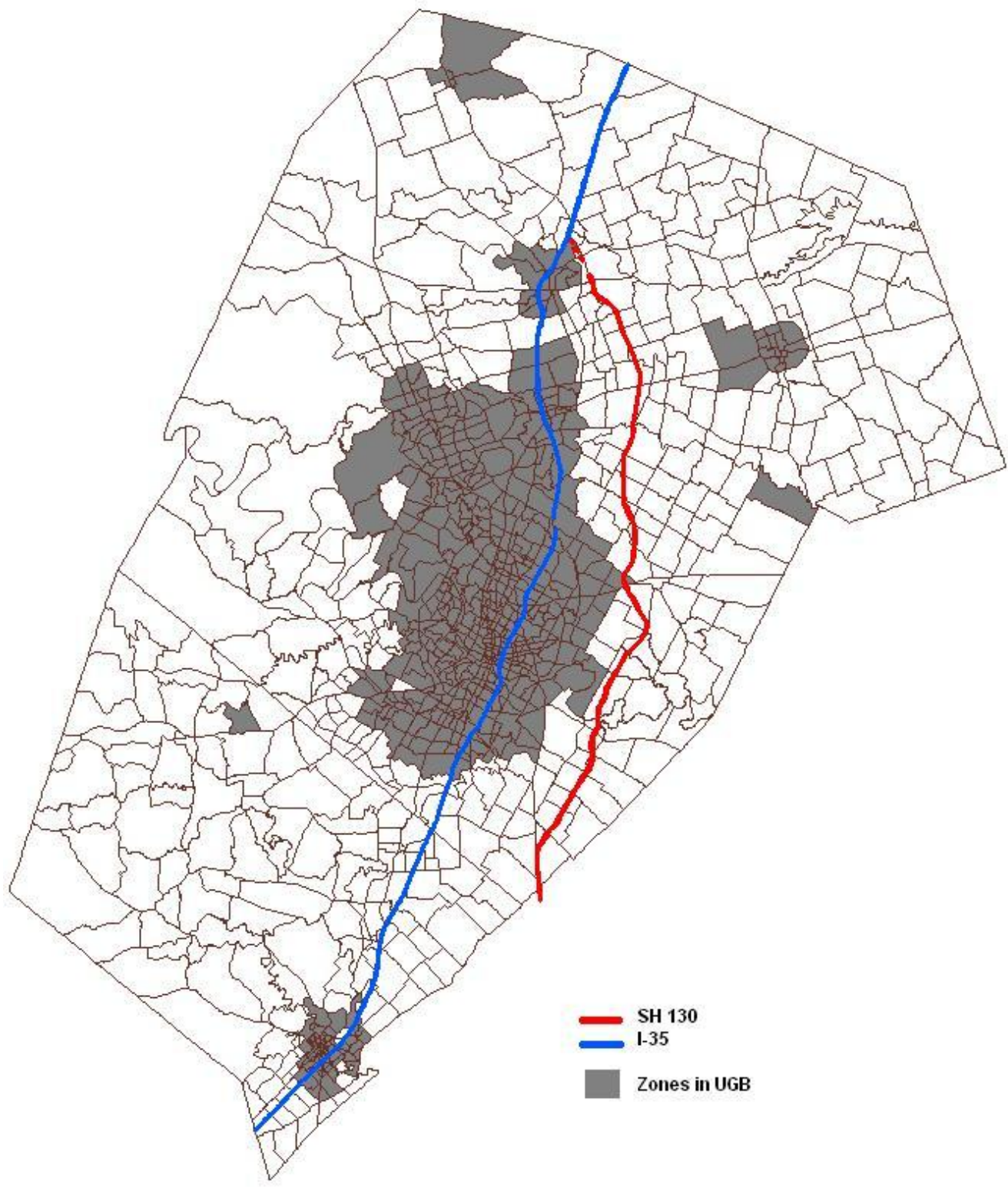

Figure 3: Illustration of Austin's Example Urban Growth Boundary, I-35 Corridor and SH 130 Corridor 


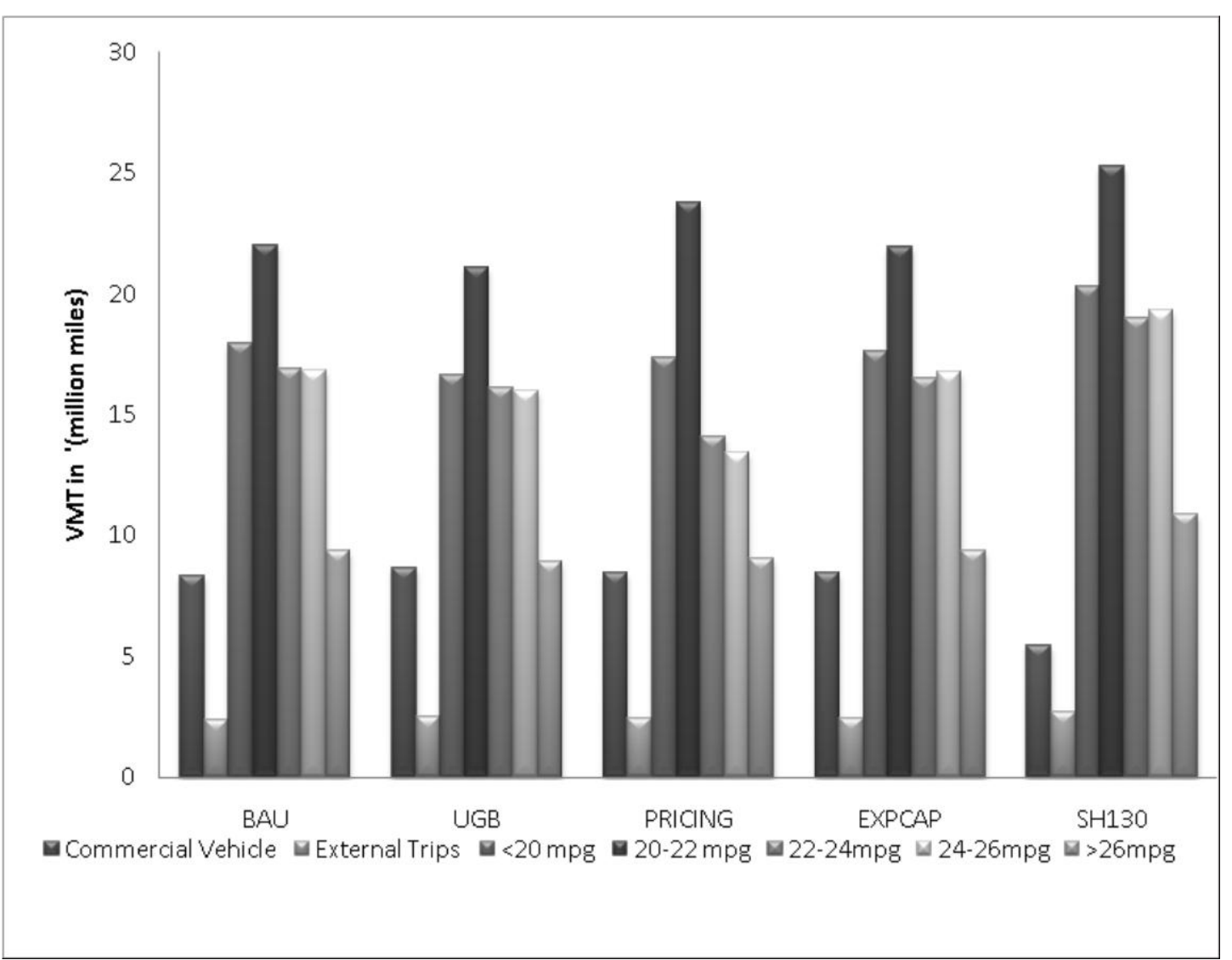


Table 1: Vehicle Fleet Composition Estimates in 2030 by Scenario

\begin{tabular}{|c|c|c|c|c|c|c|c|c|c|c|}
\hline \multirow[b]{2}{*}{ Variable } & \multicolumn{2}{|c|}{$\mathbf{B A U}$} & \multicolumn{2}{|c|}{ UGB } & \multicolumn{2}{|c|}{ PRICING } & \multicolumn{2}{|c|}{ EXPCAP } & \multicolumn{2}{|c|}{ SH130 } \\
\hline & Count & $\%$ & Count & $\%$ & Count & $\%$ & Count & $\%$ & Count & $\%$ \\
\hline $\begin{array}{l}\text { Avg. \# vehs. } \\
\text { per household }\end{array}$ & \multicolumn{2}{|c|}{2.26} & \multicolumn{2}{|c|}{2.08} & \multicolumn{2}{|c|}{1.95} & \multicolumn{2}{|c|}{2.05} & \multicolumn{2}{|c|}{2.02} \\
\hline CUVs & 43,634 & 2.05 & 45,839 & 2.34 & 42,423 & 2.31 & 37,069 & 1.92 & 38,576 & 1.91 \\
\hline Large cars & 148,141 & 6.96 & 137,518 & 7.02 & 129,841 & 7.07 & 135,148 & 7.05 & 136,334 & 6.75 \\
\hline Luxury cars & 278,191 & 13.07 & 252,900 & 12.91 & 236,910 & 12.90 & 249,252 & 12.91 & 249,768 & 12.37 \\
\hline Midsize cars & 363,968 & 17.10 & 345,950 & 17.66 & 319,185 & 17.38 & 336,326 & 17.42 & 339,573 & 16.82 \\
\hline Pickups & 406,963 & 19.12 & 345,166 & 17.62 & 309,636 & 16.86 & 358,529 & 18.57 & 356,295 & 17.65 \\
\hline $\begin{array}{l}\text { Subcompact } \\
\text { cars }\end{array}$ & 73,858 & 3.47 & 74,244 & 3.79 & 68,135 & 3.71 & 69,698 & 3.61 & 66,662 & 3.30 \\
\hline Compact cars & 102,379 & 4.81 & 101,082 & 5.16 & 93,846 & 5.11 & 94,797 & 4.91 & 95,936 & 4.75 \\
\hline SUVs & 365,458 & 17.17 & 349,867 & 17.86 & 322,491 & 17.56 & 341,153 & 17.67 & 337,139 & 16.70 \\
\hline Vans & 343,960 & 16.16 & 306,575 & 15.65 & 292,005 & 15.90 & 308,717 & 15.99 & 398,444 & 19.74 \\
\hline
\end{tabular}


Table 2: Network VMT, Greenhouse Gas Emissions, V/C Ratios and Speeds in 2030

\begin{tabular}{|c|c|c|c|c|c|c|}
\hline & & BAU & UGB & PRICING & EXPCAP & SH130 \\
\hline \multicolumn{2}{|c|}{$\begin{array}{l}\text { VMT (million per weekday) } \\
\% \text { change as compared to BAU }\end{array}$} & 94 & $\begin{array}{r}81 \\
-13.83 \\
\end{array}$ & $\begin{array}{r}90 \\
-4.56 \\
\end{array}$ & $\begin{array}{l}100 \\
6.14\end{array}$ & $\begin{array}{r}103 \\
9.63 \\
\end{array}$ \\
\hline \multicolumn{2}{|c|}{$\begin{array}{l}\text { GHG emissions } \\
\text { ('000 metric tons of } \mathrm{CO2} \text { per year*) } \\
\% \text { change as compared to BAU }\end{array}$} & 42 & $\begin{array}{c}37 \\
-13.07\end{array}$ & $\begin{array}{c}41 \\
-4.51\end{array}$ & $\begin{array}{l}45 \\
6.30\end{array}$ & $\begin{array}{r}44 \\
3.48\end{array}$ \\
\hline & Daily & 0.62 & 0.66 & 0.63 & 0.60 & 0.60 \\
\hline $\begin{array}{l}\text { Flow-Weighted } \\
\text { Average V/C Ratios }\end{array}$ & $\begin{array}{c}\text { AM } \\
\text { MID } \\
\text { PM } \\
\text { OP }\end{array}$ & $\begin{array}{l}0.66 \\
0.58 \\
0.65 \\
0.58\end{array}$ & $\begin{array}{l}0.70 \\
0.63 \\
0.68 \\
0.65\end{array}$ & $\begin{array}{l}0.69 \\
0.59 \\
0.63 \\
0.62\end{array}$ & $\begin{array}{l}0.62 \\
0.58 \\
0.64 \\
0.56\end{array}$ & $\begin{array}{l}0.62 \\
0.58 \\
0.64 \\
0.56\end{array}$ \\
\hline & Daily & 45.20 & 43.52 & 44.59 & 46.93 & 47.70 \\
\hline $\begin{array}{l}\text { Flow-Weighted } \\
\text { Average Speeds }\end{array}$ & $\begin{array}{c}\text { AM } \\
\text { MID } \\
\text { PM } \\
\text { OP }\end{array}$ & $\begin{array}{c}34.6 \\
47.27 \\
42.27 \\
56.64\end{array}$ & $\begin{array}{l}32.88 \\
42.74 \\
39.74 \\
58.72\end{array}$ & $\begin{array}{c}36.4 \\
46.17 \\
43.17 \\
52.63\end{array}$ & $\begin{array}{l}35.52 \\
47.51 \\
44.51 \\
60.18\end{array}$ & $\begin{array}{l}35.51 \\
48.98 \\
45.98 \\
60.33\end{array}$ \\
\hline
\end{tabular}

*Annual emissions were estimated assuming 300 work-day equivalents per year. 
Table 3: Household Energy Demand and GHG Emissions over Time, by Scenario

\begin{tabular}{|c|c|c|c|c|c|c|c|c|}
\hline & & $\begin{array}{l}\text { Electricity } \\
\text { demand } \\
\text { (MWh } \\
\text { /year) }\end{array}$ & $\begin{array}{l}\text { Electricity } \\
\text { demand per } \\
\text { household } \\
\text { (kWh/year ) }\end{array}$ & $\begin{array}{l}\text { Annual } \\
\text { CO2e } \\
\text { emissions } \\
\text { from } \\
\text { electricity }\end{array}$ & $\begin{array}{l}\text { Natural } \\
\text { gas ('000 } \\
\text { ccf/year) }\end{array}$ & $\begin{array}{l}\text { Natural } \\
\text { gas per } \\
\text { household } \\
\text { (ccf/year) }\end{array}$ & $\begin{array}{l}\text { Annual } \\
\text { CO2e from } \\
\text { natural gas }\end{array}$ & $\begin{array}{l}\text { Total } \\
\text { annual } \\
\text { CO2e } \\
\text { emissions }\end{array}$ \\
\hline 2005 & & $6,866,971$ & 15,226 & 10,025 & 115,403 & 256 & 1,384 & 11,410 \\
\hline $\begin{array}{l}2030 \\
\% \text { change }\end{array}$ & BAU & $\begin{array}{c}12,772,262 \\
86.12\end{array}$ & $\begin{array}{c}13,521 \\
-11.2\end{array}$ & $\begin{array}{c}18,648 \\
86.12\end{array}$ & $\begin{array}{c}238,984 \\
107.09\end{array}$ & $\begin{array}{c}253 \\
-1.09\end{array}$ & $\begin{array}{c}2,868 \\
107.09\end{array}$ & $\begin{array}{l}21,515 \\
88.56\end{array}$ \\
\hline 2030 & \multirow{2}{*}{ UGB } & $11,656,095$ & 12,340 & 17,018 & 231,455 & 245 & 2,777 & 19,795 \\
\hline$\%$ change & & 69.74 & -18.96 & 69.74 & 100.56 & -4.20 & 75.9 & 73.43 \\
\hline 2030 & \multirow{2}{*}{ Pricing } & $12,718,493$ & 13,464 & 18,569 & 236,651 & 251 & 2,840 & 21,409 \\
\hline$\%$ change & & 85.21 & -11.58 & 85.23 & 105.06 & -2.14 & 105.20 & 87.63 \\
\hline 2030 & \multirow{2}{*}{ EXPCAP } & $12,724,657$ & 13,470 & 18,578 & 238,067 & 250 & 2,857 & 21,435 \\
\hline$\%$ change & & 85.30 & -11.53 & 85.32 & 106.29 & -1.56 & 106.43 & 87.86 \\
\hline 2030 & \multirow{2}{*}{ SH 130} & $12,99,5890$ & 13,757 & 18,974 & 236,067 & 249 & 2,833 & 21,807 \\
\hline$\%$ change & & 89.25 & -9.65 & 89.27 & 104.56 & -2.38 & 104.70 & 91.12 \\
\hline
\end{tabular}


Table 4: Year 2030 per Capita Carbon Emissions Forecasts

\begin{tabular}{|c|c|c|c|c|c|}
\hline & BAU & UGB & PRICING & EXPCAP & SH130 \\
\hline $\begin{array}{l}\text { Transportation energy demand } \\
\text { Daily VMT (million) }\end{array}$ & 94 & 81 & 90 & 100 & 103 \\
\hline $\begin{array}{l}\text { Daily carbon emissions (' } 000 \text { metric tons of } \\
\mathrm{CO} 2 \text { ) }\end{array}$ & 42 & 37 & 41 & 45 & 44 \\
\hline $\begin{array}{l}\text { Annual carbon emissions per capita (metric } \\
\text { tons) }\end{array}$ & 5.51 & 4.82 & 5.28 & 5.86 & 5.69 \\
\hline Annual average VMT per capita & 10,293 & 8,993 & 9,859 & 10,943 & 10,618 \\
\hline $\begin{array}{l}\text { Residential energy demand } \\
\text { Electricity emissions (' } 000 \text { metric tons of } \\
\mathrm{CO} 2 \text { ) }\end{array}$ & 8325 & 7597 & 8290 & 8294 & 8471 \\
\hline $\begin{array}{l}\text { Natural gas emissions ('000 metric tons of } \\
\mathrm{CO} 2 \text { ) }\end{array}$ & 1280 & 1240 & 1268 & 1275 & 1265 \\
\hline $\begin{array}{l}\text { Annual carbon emissions per capita (metric } \\
\text { tons) }\end{array}$ & 4.16 & 3.83 & 4.14 & 4.15 & 4.22 \\
\hline $\begin{array}{l}\text { Total annual carbon emissions per capita } \\
\text { (metric tons) }\end{array}$ & 9.68 & 8.65 & 9.42 & 10.01 & 9.91 \\
\hline
\end{tabular}

